\title{
Pulmonary effects of short term selenium deficiency
}

\author{
Douglas B Coursin, H P Cihla
}

\begin{abstract}
Background - Selenium dependent glutathione peroxidase $(\mathrm{GPx})$ reduces hydrogen peroxide $\left(\mathrm{H}_{2} \mathrm{O}_{2}\right)$ and organic hydrogen peroxides in both normal and pathological states. Chronic dietary deficiency of selenium results in a gradual decrease in GPX and altered response to environmental stress. However, glutathione-S-transferase (GST) isozymes may increase and compensate for chronic GPx deficiency. The pattern of antioxidant enzyme activity and immunolocalisation of various enzymes in rat lung has not been described in short term ( $<3$ weeks) acute selenium deficiency.
\end{abstract}

Methods - The time course of GPx depletion from rat lung (measured every five days in subgroups of rats) during acute dietary selenium deficiency was evaluated. After 20 days of depletion, enzyme activity of lung GPx, catalase, superoxide dismutase (SOD), glutathione reductase (GR), glucose-6-phosphodiesterase (G-6PD), and GST were determined. Immunohistochemical localisation of GPx and SOD was also performed. The response to lethal hyperoxia $(>95 \%)$ in control and selenium deficient rats was then established.

Results - At 20 days, lung GPx activity in the rats fed a selenium deficient diet was one third less than in control animals who received a normal diet, while changes in blood enzymes between control and deficient animals were similar. Other lung enzyme activities remained normal with the exception of cyanide inhibited SOD activity measured in selenium deficient rat lungs which declined to $\sim 50 \%$ of normal. Immunohistochemical localisation of GPx showed a generalised loss of the enzyme throughout the lung parenchyma with some possible sparing of activity in epithelial cells of the bronchioles. When exposed to lethal hyperoxia, selenium deficient animals were more susceptible than control rats.

Conclusions - This is the earliest time at which dietary selenium deficiency has been shown to produce moderate loss of GPx activity. This change in activity was associated with increased susceptibility to pulmonary oxidant stress. However, the role of decreased SOD activity (presumed to represent copper, zinc SOD), although unexpected, may have been a major contributor to increased damage from hyperoxia. These results emphasise the complex potential interaction of elemental deficiency with the natural antioxidant response to lethal hyperoxia.

(Thorax 1996;51:479-483)

Keywords: glutathione peroxidase, superoxide dismutase, selenium deficiency, lung tolerance, hyperoxia.

Selenium dependent glutathione peroxidase (GPx) is a primary antioxidant enzyme that reduces hydrogen peroxide and organic hydroperoxides generated by both physiological and pathological processes. ${ }^{1-3}$ Dietary deficiency of selenium produces gradual loss of GPx and an altered physiological response to environmental stress. ${ }^{4}$ Rats subjected to chronic deficiency have decreased tolerance to oxidant stress including hyperoxia. ${ }^{5-8}$ However, prolonged selenium deficiency with loss of GPx can also trigger increased levels of glutathione-S-transferase (GST) isozymes which provide a nonselenium dependent peroxidase function to compensate for loss of GPx function. ${ }^{9}$ In this respect, the significance of selenium deficiency to the mechanism of increased susceptibility to environmental oxidant stress is not clear. Nonetheless, given the susceptibility of endothelial cells to hyperoxic damage $\mathrm{e}^{10}$ and the apparent reliance of this cell type on antioxidant defence mechanisms centred on GPx,${ }^{12-14}$ the suggestion that decreased levels of GPx alone can increase susceptibility to oxidant stress bears consideration. ${ }^{7}$

It was hypothesised that short term selenium deficiency could produce a low level of depletion of GPx; this deficiency could be localised to specific lung tissue primarily dependent on GPx for antioxidant defence and would correspond with increased whole animal susceptibility to hyperoxic stress. We have utilised a relatively short dietary depletion of selenium to produce GPx loss without larger shifts in homeostasis that may result in confounding effects. The time course of acute GPx depletion was determined in rat lung and blood during 20 days of feeding with a selenium deficient diet. A broad spectrum of antioxidant enzyme activity was determined for lung and blood along with animal susceptibility to hyperoxia.

The various cell types that constitute the lung do not possess the same complement of antioxidant enzymes ${ }^{15}$ and also show differences in the response to xenobiotic toxicants such as hyperoxia. ${ }^{11}$ In deficiency studies, cells critical to the development of specific disease processes may show different patterns in the time of depletion. This study therefore also used histological localisation of enzymes by 
immunological means to determine whether cell populations highly susceptible to oxidant stress may also be primarily depleted of GPx or other enzymes affected by selenium deficiency.

\section{Methods}

ANIMAL PREPARATION

The protocols for these experiments were approved by the UW Animal Care Committee. Sprague-Dawley male rats weighing 180-200 g were obtained from the Charles River Breeding Labs (Portage, Michigan, USA) and were certified free of specific bacterial, viral, and parasitic pathogens. The rats were maintained on a 12 hour light/dark cycle and given water and feed ad libitum. Hyperoxic exposure was completed as previously described ${ }^{16}$ during which time feeding with selenium deficient or control diets was maintained.

All feed was obtained from Harlan Teklad (Madison, Wisconsin, USA) in the form of a Torula yeast based diet. The selenium deficient diet, TD 92087, contained $3.0 \mathrm{~g} / \mathrm{kg}$ methionine. ${ }^{817}$ The control diet, TD 92198, was compounded identically but with the inclusion of $0.15 \mathrm{ppm}(\mu \mathrm{g} / \mathrm{g})$ sodium selenite.

\section{BIOCHEMICAL AND IMMUNOHISTOCHEMICAL} ANALYSIS

The LSAB2 kit and reagents for immunohistochemistry were obtained from Dako Corporation (Carpinteria, California, USA). Whole rabbit antisera to GPx and copper, zinc superoxide dismutase (CuZn SOD) were produced and characterised as previously described $^{15}$ and were kindly supplied by Dr Larry Oberley of the University of Iowa. All other reagents were obtained from Sigma Chemical Co. (St Louis, Missouri, USA).

\section{Biochemical assay}

Lung samples were collected from rats for biochemical assays and processed as previously described $^{16}$ with homogenisation in $50 \mathrm{mM}$ potassium phosphate buffer, $\mathrm{pH} 7 \cdot 0$, and a single freezing in liquid nitrogen for storage before analysis. Blood contamination of each lung was determined at the time of sample collection by the dithionite index method of Cross et al as modified by Tanswell and Freeman. ${ }^{1819}$ Sonicated blood samples were frozen and later assessed for biochemical activities at the same time as lung homogenates. The total activity of each homogenate was corrected for the amount of activity contributed by contaminating blood such that all activities are representative of lung tissue only.

Protein concentrations were determined by the bicinchoninic acid method ${ }^{20}$ and total DNA by the method of Downs and Wilfinger. ${ }^{21}$ Catalase and GPx, using hydrogen peroxide as substrate, were determined as previously described. ${ }^{16} \mathrm{GPx}$ activity was defined as $1 \mu \mathrm{mol}$ NADPH oxidised per minute and catalase activity was in international units. Glutathione reductase (GR) activity was measured in units of $1 \mu \mathrm{mol}$ oxidised glutathione reduced per minute using the method of Goldberg and Spooner. ${ }^{22}$ Glucose-6-phosphate dehydrogenase (G-6-PD) activity was defined as the reduction of $1 \mu \mathrm{mol}$ NADP per minute using the method of Langdon. ${ }^{23}$ GST activity was determined using 1-chloro-2,4-dinitrobenzene as substrate and was defined as $1 \mu \mathrm{mol}$ of product formed per minute. ${ }^{24}$ The method of Spitz and Oberley was used to determine total SOD activity $^{25}$ with each homogenate assayed in a series of dilutions containing from $1-400 \mu \mathrm{g}$ protein. Activity was determined from the amount of inhibition of a xanthine/xanthine oxidase standardised reaction. The assay was repeated with inclusion of $5.0 \mathrm{mM}$ sodium cyanide to inhibit $\mathrm{CuZn}$ SOD which provides a separate measurement of manganese SOD (Mn SOD) activity. One unit of activity was defined as the protein content producing half maximal inhibition. All spectrophotometric determinations were made using a Beckman DU7HS spectrophotometer.

\section{Immunohistochemical assay}

For immunohistochemical analysis rat lung samples were obtained by double perfusion fixation and further treated as previously described, ${ }^{15}$ but with the following exceptions. Four micron sections were cut and collected on slides coated with 3-aminopropyltriethoxysilane (Sigma Chemical Co.). The streptavidin-biotin linked immunostaining reagents used were as supplied by the LSAB2 kit. The greater sensitivity and lower background resulting from these reagents allowed better immunostaining for GPx and CuZn SOD than previously described, although trypsinisation of sections was still necessary for optimal localisation of extracellular GPx in elastic tissue. ${ }^{15}$ All sections were immunostained simultaneously using the same reagent preparations and antisera dilutions of 1:100. Identically treated sections were exposed to normal rabbit serum instead of primary antiserum to serve as a control. Normal rabbit serum was diluted to the same protein concentration as the antisera.

\section{DATA ANALYSIS}

Statistically significant differences were determined by two-tailed, unpaired Student's $t$ tests. Immunostaining was assessed by two blinded observers.

\section{Results}

Rats were placed on control or selenium deficient diets and lung and blood samples were obtained for biochemical analysis at five day intervals for 20 days of feeding, during which a progressive decrease in GPx activity was seen (fig 1). At all time points the levels of GPx activity for selenium deficient animals were significantly lower than control values. The 20 days of selenium deficient diet produced a loss of over $30 \%$ of normal GPx activity. The mean activities for control values did not show any 


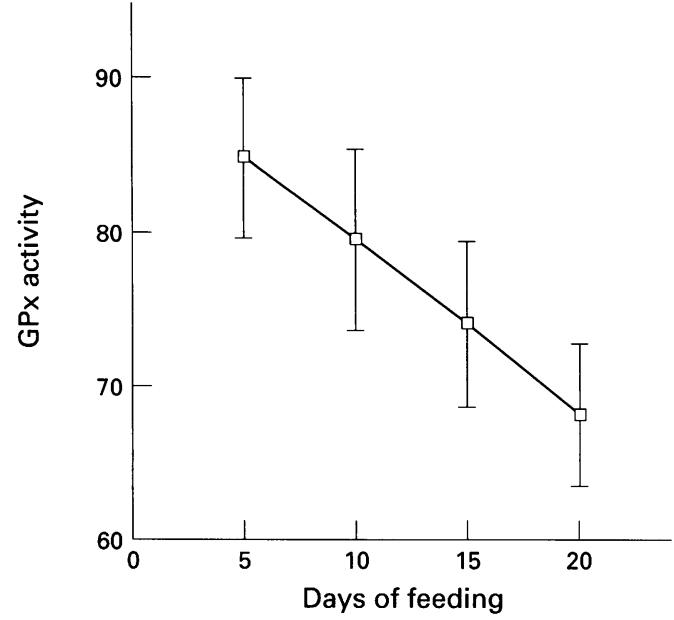

Figure 1 Loss of glutathione peroxidase(GPx) activity from the lung in rats fed a selenium deficient diet for 20 days. Data represent mean (SD) and are expressed as the percentage of the activity in control animals for each time point $(n=5$ or 6$)$.
Mean (SD) effects of dietary selenium deficiency for 20 days in rats

\begin{tabular}{|c|c|c|}
\hline & $\begin{array}{l}\text { Control } \\
(n=5)\end{array}$ & $\begin{array}{l}\text { Selenium deficient } \\
(n=5)\end{array}$ \\
\hline Body weight (kg) & $(0 \cdot 01)$ & $0.30 \quad(0.01)$ \\
\hline Lung weight $(\mathrm{g})$ & $(0.09)$ & $1.00 \quad(0.06)$ \\
\hline Lung:body weight ratio & $3.56 \quad(0.32)$ & $3.34 \quad(0.22)$ \\
\hline \multicolumn{3}{|l|}{ Lung biochemistry } \\
\hline mg protein/mg DNA & $81 \cdot 7(19 \cdot 0)$ & $83 \cdot 9(12 \cdot 7)$ \\
\hline GPx (units/mg DNA) & $14 \cdot 7(3 \cdot 1)$ & $9.9(1.9)^{*}$ \\
\hline GST (units/mg DNA) & $7 \cdot 7 \quad(2 \cdot 1)$ & $7 \cdot 9(1 \cdot 1)$ \\
\hline GR (units/ $\mu \mathrm{g}$ DNA) & $2 \cdot 8 \quad(0 \cdot 7)$ & $3.0 \quad(0.6)$ \\
\hline G-6-PD (nm/min $/ \mu \mathrm{g}$ DNA) & $3 \cdot 3(0 \cdot 7)$ & $3.6(1.0)$ \\
\hline Catalase (units $/ \mathrm{min} / \mu \mathrm{g}$ DNA) & $3.9(0.8)$ & $4 \cdot 1 \quad(1 \cdot 1)$ \\
\hline \multicolumn{3}{|l|}{ SOD (units/ $\mu \mathrm{g}$ DNA) } \\
\hline Total & $31 \cdot 5 \quad(3 \cdot 8)$ & $18 \cdot 3(1.9)^{*}$ \\
\hline Cyanide inhibited & $5.9(0.6)$ & $5 \cdot 6(1 \cdot 1)$ \\
\hline Cyanide resistant & $\sim 25 \cdot 6$ & $\sim 12 \cdot 7$ \\
\hline
\end{tabular}

$\mathrm{GPx}=$ glutathione peroxidase; GST=glutathione-S-transferase; $\mathrm{GR}=$ glutathione reductase; G-6-PD = glucose-6-phosphate dehydrogenase; SOD = superoxide dismutase. $* \mathrm{p}<0.05$ (Student's two tailed unpaired $t$ test).

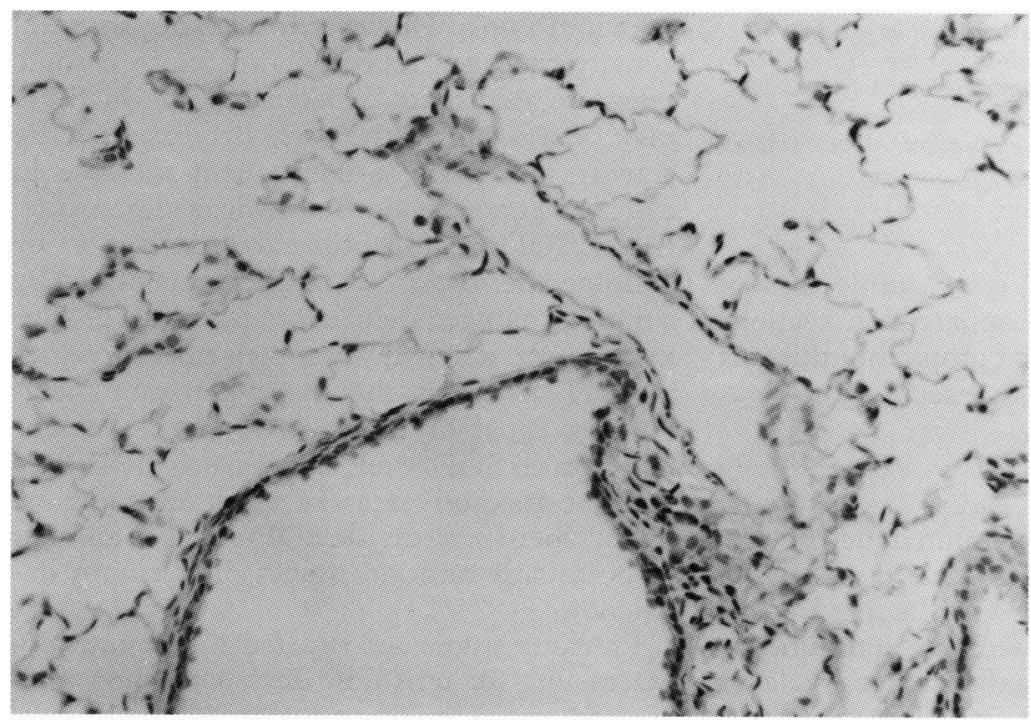

Figure 2 Immunostaining of lung sections using normal rabbit serum instead of primary antisera showing normal background staining together with nuclear staining primarily due to the haematoxylin counterstain. This lung sample was obtained from an animal fed control diet but is representative of results from lung sections from selenium deficient rats treated with normal rabbit serum. Magnification $\times 260$ reduced to $62 \%$ in origination. significant changes between the different time points (pooled mean (SD) activity $=0 \cdot 19$ $(0 \cdot 02)$ units $/ \mathrm{mg}$ protein, $\mathrm{n}=21)$.

BIOCHEMICAL

Animals maintained on the selenium deficient diet for 20 days appeared grossly normal and their lungs were histologically normal. However, they had a $10 \%$ decrease in lung weight compared with control animals $(p=0.05)$, although body weights and lung:body weight ratios were statistically normal as were lung protein:DNA ratios (table). Further biochemical effects of this treatment are detailed in the table. Besides loss of GPx activity, total SOD activity was also significantly less for the selenium deficient group, while the cyanide inhibited assay showed no change from normal levels. All other parameters were normal. No significant differences in enzyme activities were found in the blood samples from control or selenium deficient groups (data not shown). Blood GPx activity for the selenium deficient group was approximately $76 \%$ that of the control group, but this was not a significant difference.

\section{HYPEROXIC EXPOSURE}

Groups of animals fed the control or selenium deficient diets were placed into an environment of $95 \%$ oxygen after 20 days and the specific diet continued. The mean (SE) time until death for the selenium deficient group was $73 \cdot 8(1 \cdot 9)$ hours $(n=9)$, while control animals survived a mean of $97.5(2.0)$ hours $(n=8)$. This difference was significant.

\section{IMMUNOHISTOCHEMICAL}

Histological sections of lung immunostained for GPx showed that the enzyme was predominantly localised in the bronchiolar epithelial cells with less marked labelling of the periarteriolar and peribronchiolar muscularis (figs 2 and 3). Moderate staining of all the cellular elements of alveolar tissue was also seen. Trypsinised sections also demonstrated marked labelling of elastic tissue in areas surrounding alveolar ducts, blood vessels, and airways. Selenium deficiency produced a general loss of immunostaining for GPx throughout the lung (fig 4). Parenchymal lung tissue showed only minimal immunostaining which barely exceeded that of the control sections following exposure to normal rabbit serum instead of primary antisera. Immunostaining of the bronchiolar epithelium and the muscle coats of the airways and blood vessels was also markedly diminished. Clara cells retained more intense staining than other lung cells. Tissue sections immunostained for $\mathrm{CuZn}$ SOD showed minor differences between treated and control groups (data not shown). In both groups considerable staining occurred in the epithelial cells of the bronchioles, less intense staining was observed in endothelial cells and the smooth muscle cells of arterioles, and only minimal staining was seen in all other cellular 


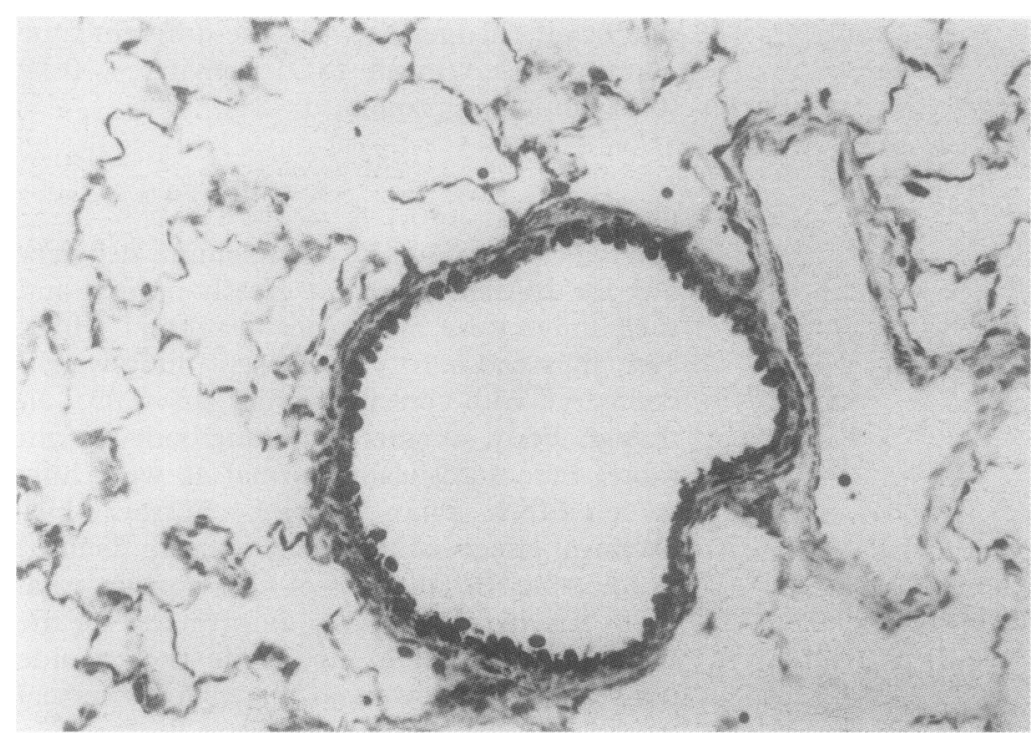

Figure 3 Lung section of a control animal showing a normal distribution of glutathione peroxidase $(G P x)$ following immunolocalisation. This untrypsinised section shows diffuse staining of the pulmonary parenchyma, dense staining of bronchiolar epithelial cells, especially Clara cells, and marked staining of the muscle cells of both the bronchiole and arteriole. Magnification $\times 260$, reduced to $62 \%$ in origination.

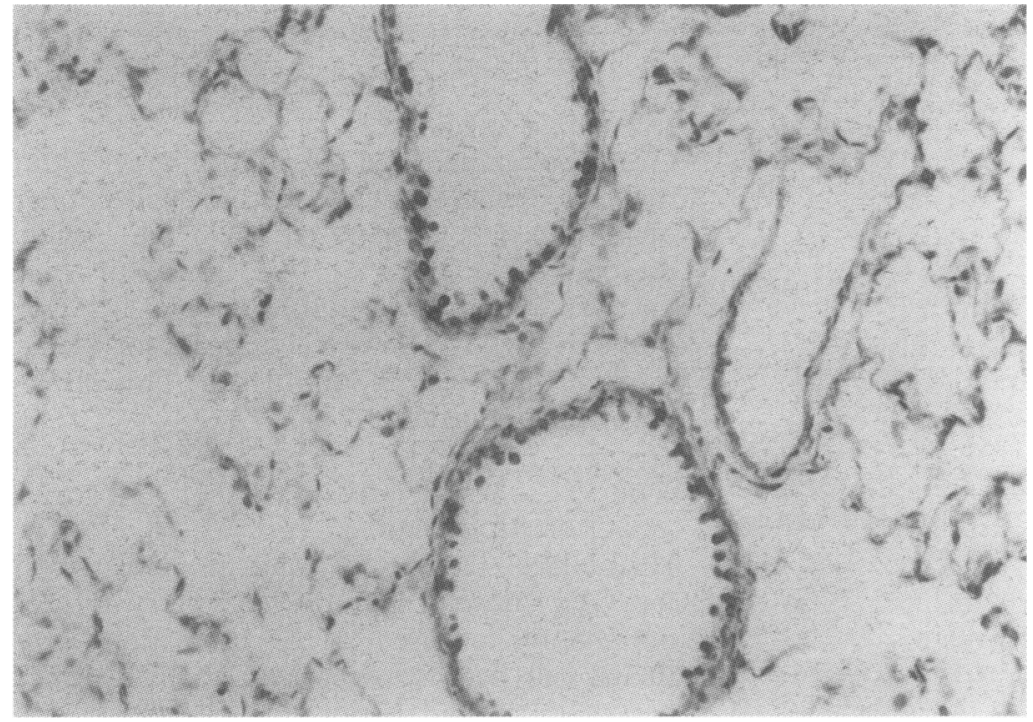

Figure 4 Section of a selenium deficient lung showing loss of glutathione peroxidase $(G P x)$ throughout the tissues of the lung following immunolocalisation compared with the normal lung section (fig 3). Note that parenchymal lung immunostaining barely exceeds that of the normal rabbit serum control (fig 2). Although diminished, immunostaining of Clara cells is maintained compared with that of other cells. Magnification $\times 260$, reduced to $62 \%$ in origination.
Short term deficiency of selenium for 20 days produced a linear decrease in lung GPx activity that was consistent with findings of lung enzyme levels following more prolonged periods of deficiency, but of smaller magnitude. ${ }^{67}$ At 20 days the lung deficiency effects were mainly confined to loss of GPx activity; no changes in blood levels of enzyme were observed, compensatory increases in GST did not occur, and the activities of catalase and enzymes of the glutathione reductase cycle remained unchanged. The increased activity of GST previously shown to be dependent on loss of GPx activity may also be dependent on prolonged deficiency and greater enzyme loss, and this study was probably terminated before GST induction occurred. Lack of changes in the blood levels of GPx or levels of catalase in the lung is consistent with previous studies and reinforces the observation that blood enzyme activity does not adequately reflect tissue levels. ${ }^{8}$

Total SOD activity was also decreased in the selenium deficient rats. Activity following cyanide inhibition was the same for both groups, which suggests normal levels of $\mathrm{Mn}$ SOD (cyanide resistant) but a significant loss of $\mathrm{CuZn}$ SOD (cyanide inhibited) activity in selenium deficient animals of about $50 \%$ of normal as estimated by calculation. This was an unexpected result. The manner in which the test diets were compounded precludes the possibility of an additional, concurrent dietary deficiency of either copper or zinc as the selenium deficient diet was supplemented with selenite to form the control diet. Another possibility is that a common pathway occurs in the metabolic control of GPx and CuZn SOD, perhaps related to the unexplained effects of copper deficiency on both CuZn SOD and $\mathrm{GPx} .{ }^{26}$ Loss of GPx activity following selenium deficiency is a post-transcriptional change, mRNA levels are maintained, ${ }^{27} 28$ and loss of activity precedes loss of immunoreactive protein. ${ }^{29}$ This would suggest that loss of $\mathrm{CuZn}$ SOD would be a more direct effect of decreased selenium pools. However, no change in SOD activity has been reported after more chronic selenium deficiency. ${ }^{6}$ Decreased CuZn SOD may be a result of the early decrease in GPx activity and possible consequent increase in cytosolic concentrations of hydrogen peroxide. CuZn SOD is susceptible to inactivation by hydrogen peroxide, ${ }^{3031}$ an effect ameliorated by a more prolonged deficiency and with a greater loss of GPx activity by compensatory increases in GST isozymes that have peroxide metabolising capability. ${ }^{9}$ However, given the limited data on SOD levels after chronic deficiency and the method of assay used, it would be important to reassess the SOD status of animals at both early and late stages of selenium deficiency.

Previous studies of rats fed a selenium deficient diet for up to 50 days have shown increased susceptibility to hyperoxic lung injury with lung GPx levels of $25-33 \%$ those of controls. ${ }^{67}$ An additional study with 28 days of feeding also caused a reduction of lung GPx levels in treatment animals that was apspecies, (b) this decrease in GPx activity was associated with increased susceptibility to hyperoxia, and (c) it was possible to localise loss of GPx activity to specific cell populations most susceptible to oxygen toxicity. 
proximately a quarter of control values. ${ }^{8}$ This exceeds the duration of depletion suggested by our study and previous studies, but may be dependent on the method used for calculating enzyme activities. Nonetheless, this 28 day study also demonstrated increased susceptibility to hyperoxia. In our study rats subjected to 20 days of selenium deficiency had an increased susceptibility to $95 \%$ oxygen which was surprising since GPx activity was decreased to only about $30 \%$ below normal. However, with the coincident decrease in $\mathrm{CuZn}$ SOD activity, these animals had impaired detoxification mechanisms for both superoxide and hydroperoxide that was increased with exposure to hyperoxia. These combined effects may have contributed substantially to the loss of normal tolerance to pulmonary oxidant stress exhibited by selenium deficient rats.

Immunohistochemical localisation of GPx distinguished a general loss throughout the cells of the lung parenchyma, including pulmonary endothelial cells which may be particularly susceptible to damage by hyperoxia ${ }^{10}$ and dependent on GPx as a detoxification mechanism. ${ }^{12-14}$ Immunostaining for CuZn SOD showed no change in selenium deficient animals compared with normal control rats although biochemical activity was considerably decreased. This would also be consistent with the hypothesis that $\mathrm{CuZn} \mathrm{SOD}$ protein is being inactivated but is still present and immunologically reactive. However, the immunohistochemical method employed in this study is qualitative and only roughly quantitative. It is therefore not known if the $50 \%$ reduction in $\mathrm{CuZn}$ SOD could be identified by light microscopic immunohistochemistry.

This is the earliest point at which selenium deficiency has resulted in increased pulmonary susceptibility to subsequent oxidant stress. While moderate depletion of GPx was obtained without increases in GST activity, the apparent loss of $\mathrm{CuZn}$ SOD activity was unexpected and could contribute substantially to the loss of pulmonary tolerance to the increased reactive oxygen species generated by hyperoxic exposure. This is a finding of considerable significance to the understanding and interpretation of results from models using selenium deficiency and needs to be addressed more fully. These findings further emphasise the complex temporal interaction of elemental deficiencies with the natural antioxidant response to hyperoxia.

Supported in part by a General Research Grant to the University of Wisconsin Clinical Science Center from the National Institutes of Health and by the University of Wisconsin Department of Anesthesia Research and Development Fund.

1 Flohé L. Glutathione peroxidase brought into focus. In: Pryor WA, ed. Free radicals in biology. Vol V. New York: Academic Press, 1982:223-54.

2 Heffner JE, Repine JE. Pulmonary strategies of antioxidant defense. Am Rev Respir Dis 1989;140:531-54.

3 Jamieson D. Oxygen toxicity and reactive oxygen metabolites in mammals. Free Radic Biol Med 1989;7:87-108.
tamieson
4 Nève J, Vertongen F, Molle L. Selenium deficiency. Clin Endocrinol Metab 1985;14:629-56.

5 Jenkinson SG, Spence, Jr. TH, Lawrence RA, Hill KE, Duncan CA, Johnson KH. Rat lung glutathione release: response to oxidative stress and selenium deficiency. $f$ Appl Physiol 1987;62:55-60.

6 Cross CE, Hasegawa G, Reddy KA, Omaye ST. Enhanced lung toxicity of $\mathrm{O}_{2}$ in selenium-deficient rats. Res Commun lung toxicity of $\mathrm{O}_{2}$ in selenium-deficient rats.

7 Deneke SM, Gershoff SN, Fanburg BL. Changes in $\mathrm{O}_{2}$ toxicity and glutathione peroxidase levels in selenium deficient rats. Chest 1983;5:39S-40S.

8 Forman HJ, Rotman EI, Fisher AB. Roles of selenium and sulfur-containing amino acids in protection against oxygen toxicity. Lab Invest 1983;49:148-53.

9 Jenkinson SG, Lawrence RA, Burk RF, Gregory PE. Nonselenium-dependent glutathione peroxidase activity in rat lung: association with lung glutathione $\mathrm{S}$-transferase activity and the effects of hyperoxia. Toxicol Appl Pharmacol 1983;68:399-404.

10 Crapo JD, Barry BE, Foscue HA, Shelburne J. Structural and biochemical changes in rat lungs occurring during exposures to lethal and adaptive doses of oxygen. Am Rev Respir Dis 1980;122:123-43.

11 Crapo JD. Morphologic changes in pulmonary oxygen toxicity. Ann Rev Physiol 1986;48:721-31.

12 Harlan JM, Levine JD, Callahan KS, Schwartz BR, Harker LA. Glutathione redox cycle protects cultured endothelial cells against lysis by extracellularly generated hydrogen peroxide. F Clin Invest 1984;73:706-13.

13 Raes M, Michiels C, Remacle J. Comparative study of the enzymatic defense systems against oxygen-derived free radicals: the key role of glutathione peroxidase. Free Radic Biol Med 1987;3:3-7.

14 Suttorp N, Kästle S, Neuhof H. Glutathione redox cycle is an important defense system of endothelial cells against an important defense system of endothelial
chronic hyperoxia. Lung 1991;169:203-14.

15 Coursin DB, Cihla HP, Oberley TD, Oberley LW. Immunolocalisation of antioxidant enzymes and isozymes of glutathione S-transferase in normal rat lung. Am F Physiol 1992;263:L679-91.

16 Coursin DB, Cihla HP, Will JA, McCreary JL. Adaptation to chronic hyperoxia: biochemical effects and the response to subsequent lethal hyperoxia. Am Rev Respir Dis 1987; 135:1002-6.

17 Waschulewski IH, Sunde RA. Effect of dietary methionine on utilisation of tissue selenium from dietary selenomethionine for glutathione peroxidase in the rat. $f$ Nutr 1988;118:367-74.

18 Cross CE, Watanabe TT, Hasegawa GK, Goralnik GN, Roertgen KE, Kaisu T, et al. Biochemical assays in lung hoertgen KE, Kaisu $\mathrm{T}$, et al. Biochemical assays in lung homogenates: artifacts caused by trapped blood
fusion. Toxicol Appl Pharmacol 1979;48:99-109.

19 Tanswell AK, Freeman BA. Pulmonary antioxidant enzyme maturation in the fetal and neonatal rat. I. Developmental profiles. Pediatr Res 1984;18:584-7.

20 Smith PK, Krohn RI, Hermanson GT, Mallia AK, Gartner FH, Provenzano MD, et al. Measurement of protein using bicinchoninic acid. Anal Biochem 1985;150:76-85.

21 Downs TR, Wilfinger WW. Fluorometric quantification of DNA in cells and tissue. Anal Biochem 1983;131:538-47.

22 Goldberg DM, Spooner RL. Glutathione reductase. In: enzymatic analysis. Volume III: Enzymes 1: Oxidoreductases, transferases. 3rd edn. Weinheim:Verlag Chemie,1989:25865.

23 Langdon RG. Glucose 6-phosphate dehydrogenase from erythrocytes. Methods Enzymol 1966;9:126-31.

24 Habig WH, Jakoby WB. Assays for differentiation of glutathione $S$-transferases. Methods Enzymol 1981;77:398405.

25 Spitz DR, Oberley LW. An assay for superoxide dismutase activity in mammalian tissue homogenates. Anal Biochem 1989;179:8-18.

26 Jenkinson SG, Lawrence RA, Burk RF, Williams DM. Effects of copper deficiency on the activity of the selenoenzyme glutathione peroxidase and on excretion and tissue enzyme glutathione peroxidase and on excretion

$27 \mathrm{Li} \mathrm{N}$, Reddy PS, Thyagaraju K, Reddy AP, Hsu BL, Scholz $\mathrm{RW}$, et al. Elevation of rat liver mRNA for seleniumdependent glutathione peroxidase by selenium deficiency. f Biol Chem 1990;265:108-13.

28 Chang M, Reddy CC. Active transcription of the seleniumdependent glutathione peroxidase gene in selenium-deficient rats. Biochem Biophys Res Commun 1991;181:14316.

29 Knight SAB, Sunde RA. The effect of progressive selenium deficiency on antiglutathione peroxidase antibody reactive protein in rat liver. $\mathcal{F}$ Nutr $1987 ; 117: 732-8$.

30 Bray RC, Cockle SA, Fielden EM, Roberts PB, Rotitio G, Calabrese $L$. Reduction and inactivation of superoxide dismutase by hydrogen peroxide. Biochem $\mathcal{f} 1974 ; 139$ : 43-8.

31 Hodgson EK, Fridovich I. The interaction of bovine erythrocyte superoxide dismutase with hydrogen peroxide: in activation of the enzyme. Biochemistry 1975;14:5294-9. 